\title{
Experiencing Positive Health, as a Family, While Living With a Rare Complex Disease: Bringing Participatory Medicine Through Collaborative Decision Making Into the Real World
}

Caridi Family ${ }^{1}$; Annapurna Poduri ${ }^{2}$, MD, MPH; Orrin Devinsky ${ }^{3}$, MD; Miriam Tabacinic ${ }^{4}$, MD; Alejandro R Jadad ${ }^{5}$, MD, DPhil

\footnotetext{
${ }^{1}$ The Caridi Family, Aventura, FL, United States

${ }^{2}$ Epilepsy \& Clinical Neurophysiology, Boston Children's Hospital, Harvard University, Boston, MA, United States

${ }^{3}$ Comprehensive Epilepsy Center and the Saint Barnabas Institute of Neurology and Neurosurgery, New York University, New York, NY, United States

${ }^{4}$ T Design, Miami, FL, United States

${ }^{5}$ Dalla Lana School of Public Health, University of Toronto, Toronto, ON, Canada
}

\section{Corresponding Author:}

Alejandro R Jadad, MD, DPhil

Dalla Lana School of Public Health

University of Toronto

155 College St

Toronto, ON, M5T 3M7

Canada

Phone: 14163585631

Email: ajadad@gmail.com

\begin{abstract}
Physician-patient collaboration was recognized as a critical core of participatory medicine more than a century ago. However, the subsequent focus on scientific research to enable cures and increased dominance of physicians in health care subordinated patients to a passive role. This paternalistic model weakened in the past 50 years-as women, minorities, and the disabled achieved greater rights, and as incurable chronic diseases and unrelieved pain disorders became more prevalent—promoting a more equitable role for physicians and patients. By 2000, a shared decision-making model became the pinnacle for clinical decisions, despite a dearth of data on health outcomes, or the model's reliance on single patient or solo practitioner studies, or evidence that no single model could fit all clinical situations. We report about a young woman with intractable epilepsy due to a congenital brain malformation whose family and medical specialists used a collaborative decision-making approach. This model positioned the health professionals as supporters of the proactive family, and enabled them all to explore and co-create knowledge beyond the clinical realm. Together, they involved other members of the community in the decisions, while harnessing diverse relationships to allow all family members to achieve positive levels of health, despite the resistance of the seizures to medical treatment and the incurable nature of the underlying disease.
\end{abstract}

(J Participat Med 2020;12(2):e17602) doi: $\underline{10.2196 / 17602}$

\section{KEYWORDS}

collaboration; shared decision making; patient-physician relationship; communication; partnership; participatory medicine

\section{Introduction}

Collaboration between physicians and patients in a mutual relationship — the core attribute of participatory medicine-was first documented in the late 19th century [1]. Bertha Pappenheim (also known as Anna O.) and Dr Josef Breuer, her physician and Freud's mentor, discovered the therapeutic power of a collaborative partnership in the 1880 s while listening to and learning from each other [2]. In the late 1950s, the mutual participation model was relegated to psychoanalysis and psychology. Traditional medicine favored models that had existed since Ancient Egypt, which placed physicians as the dominant members of the relationship, and patients mostly as passive or inactive beings. These paternalistic, priestly, or passive models [3-5] pervaded 20th century medicine, driven by a hierarchical view of knowledge, with physicians at the apex and patients/families at the base, a reductionist chemical-mechanical view of people, a pathophysiological 
approach to illness, and a belief that science could conquer disease and even defeat death [6].

As most acute conditions (eg, infections, diabetic coma, appendicitis) became curable, chronic incurable diseases dominated, leading to models based on doing things to patients [7]. This approach to chronic disease is rife with limitations, and in some cases (eg, chronic pain and psychiatric disorders), modern medical approaches may do more harm than good. By the early 21 st century, a shared decision-making model had gained ascendance as the pinnacle for clinical decisions, particularly within the context of evidence-based medicine and patient-centered care [8-11]. Even though there are multiple ways to conceptualize it, in essence, shared decision making incorporates at least two participants-typically 1 physician and 1 patient - who examine information about different options to manage a condition, taking steps to build a consensus and to agree about which one to implement [12].

The shared decision-making model echoes and builds on precursors from the mid-1900s, which failed to cross from theory into clinical practice. Current approaches reflect the reaction against paternalism in the physician-patient relationship. They received names such as mutual participation or collegial models [3,7], and were also regarded as alternatives to another model, which considers physicians as the main source of facts and synthetic advice, for patients to weigh relative values and make the diagnostic or therapeutic decisions. These have been labeled consumerist, informative, informed, autonomous, or engineering models [3,7,13-16]. Despite being touted as the ultimate model, several systematic reviews of shared decision making reveal a dearth of supportive evidence, leaving their impact on empirical health outcomes uncertain $[10,17-23]$

Others observed that most research on shared decision making does not match clinical reality, because studies focus on a single patient with a solo practitioner. Instead, the real-life situations employ the model with patients who do not want to make decisions alone, preferring their loved ones to be involved or take charge in making critical decisions, and with multiple specialists participating in their care [24]. Besides, patient preferences for a shared decision-making model vary across studies according to their date of completion, as well as the selected population and the measurement tools used [25]. Further, the sheer diversity of models of relationship might indicate that the needs and preferences of patients and clinicians differ, and that existing models are components of a menu from which to choose, rather than single, fixed options to use during their interactions [26].

Our case illustrates how a new model, collaborative decision making, enabled a family and a group of involved health professionals to overcome all of the aforesaid limitations. This new approach, which was proposed in this journal in 2010 as an invitation to those involved in participatory medicine to consider a shift from the shared model, is presented here as an option to enrich, rather than to replace or displace, all other options, as it could foster a stronger partnership among patients, loved ones, and professionals, encouraging them to engage in a process with the common goal of creating a plan of action aimed at improving health [27].

The description follows the parameters that reflect the range of interests of those involved in participatory medicine, and underscores the desire of an entire family that leveraged this model to find solutions not offered by leading institutions, and to bring their experiences to other patients and health professionals who could learn from it.

\section{Case Presentation}

\section{The People}

Silvana was a 14-year-old woman when she was diagnosed with subcortical band heterotopia in 2011, following a seizure during a flight. This rare condition results from millions of neurons that do not migrate properly during development, creating a brain with dense bands below the cerebral cortex, where there should only be white matter fibers connecting neurons [28]. This explained the mild learning impairment that Silvana experienced throughout her life and the drug-resistant focal epilepsy that was progressively worsening for 5 years. She had 4 different seizures types, occurring at least once per week each but some up to 30/day, and lasting 4-150 seconds. Typical seizures included a fixed stare, shaking, or trembling of one hand, without loss of awareness, followed by fatigue. Every few months, she would have a drop episode. Despite these challenges, Silvana remained a cheerful young woman, keen to be offered tasks to complete, and eager to engage in artistic pursuits, especially photography and painting. Her main concern was, consistently, not to be left alone in an enclosed environment, such as an elevator, because of her fear of injury as a result of a fall.

The severity of Silvana's condition disrupted her family's life, with her father Ricardo most affected. He was frustrated by the trial-and-error approach to the frequent changes in the dose and combination of antiseizure medications by the multiple physicians involved in her case, despite understanding the dearth of scientific evidence supporting any option over the others. Using the skills and attitudes that had enabled him to become a successful entrepreneur, such frustration was transformed into a relentless urge to become an expert on band heterotopias and to perform online searches, almost compulsively, seeking to find a silver bullet that could have been missed by all of the specialists involved in his daughter's care. He also joined groups of parents on social media, hoping to find and benefit from additional insights from the field. The frustration associated with the failure to find an effective treatment for the seizures morphed into exhaustion and anxiety so intense that he required support from psychologists and psychiatrists, with little benefit. An additional source of distress was the regret produced by the realization that he would feel much better whenever Silvana was out of his sight, especially in a different city.

Silvana's mother, Denise, faced different challenges. She accepted the problem's incurable nature and its complexity, which meant no doctor had sufficient data to guide therapy accurately, and sought to reduce its social impact. She fought the stigmatization by the family's relatives and friends as well 
as potential rejection by peers, and the interruption of Silvana's high-school studies. Given the conservative city in which they lived, the family decided not to disclose the underlying neurological condition to the school until the last year of studies, or to people outside the inner family circle. Instead, Silvana was diagnosed with a learning impairment.

Leon, Silvana's only sibling, became very supportive of his sister, while maintaining his high academic level of school performance. Even as a young child accompanying his sister to medical visits, he was able to ask pertinent questions about why this happened to his sister's brain, underscoring that the common sense questions of a child are among the most important questions that physicians should try to answer.

\section{New Knowledge Creation Through Collaboration of Researchers and Patients, as Individuals and as Groups}

By 2016, Ricardo's relentless efforts to find effective medicines to control Silvana's seizures proved fruitless. As this was making his distress overwhelming, a physician friend of the family (Miriam Tabacinic), who was aware of the collaborative decision-making model, suggested to contact its lead author (Alex Jadad), whom she knew since their postgraduate training years back in the 1980s.

Given that they were located in different regions of the continent, Ricardo and Denise held an initial virtual conversation with Alex, during which the latter explained the model, emphasizing the need for a shift from a focus on the fight against the disease to one devoted to the enjoyment of health, and from Silvana to Ricardo as the person most in need of support.

Ricardo's level of distress was extremely high and reducing it became the first priority. Because of his compulsive desire to cure Silvana's seizures and the large swaths of time he was spending searching the biomedical literature and consulting specialists in different regions of the world, it was agreed that a formal synthesis of the literature on treatment-resistant epilepsy would be conducted, and that the leading authors would be invited to join a panel to discuss Silvana's case and the best course of action.

The synthesis, which included papers indexed by MEDLINE and EMBASE from January 2015 to June 2016, was complemented by screening of all of the citations of relevant articles, and a forward search, using Google Scholar.

This systematically individualized effort to search, screen, and distill the peer-reviewed and gray literature revealed many options with a high probability of success still available to Silvana, including cannabidiol and other cannabinoids; conventional, first-line antiepileptic drugs; ketogenic or modified Atkins diets; noninvasive neurostimulation methods; experimental drugs; vagus nerve stimulation; or corpus callosotomy.

\section{Health Professionals and Health-Related Institutions}

The relevant articles identified potential experts who were invited to become panel members to hold an in-depth discussion about which options to pursue (see Acknowledgments). They included Orrin Devinsky (Panel Chair, who also was Silvana's current treating physician) and Annapurna (Ann) Poduri, another physician in Silvana's team who managed her as a teenager and was highly trusted by her family.

The group acknowledged that a diverse panel of experts provided an opportunity for new insights to emerge to maximize Silvana's health, while reassuring Ricardo and the family about the robustness of the recommendations. The panel held one whole-group session, chaired by Orrin, using a digital videoconferencing platform, which was followed by on-demand ad hoc email exchanges. After multiple interactions, invasive options were unacceptable to the family. Instead, it was decided to try a modified Atkins diet coupled with different combinations of conventional pharmacological interventions, leaving transcranial stimulation and experimental drugs to be considered at a later stage.

As Silvana was now an adult, it was agreed that Orrin would act as the main treating physician, working closely with Ann, to ensure continuity of care.

\section{Contextual Determinants}

The rigor of the panel, the commitment of its members, and the open and comprehensive way in which Ricardo's questions were addressed enabled a major shift. The family's near-exclusive focus on the illness and its symptoms was broadened and redirected to a more constructive emphasis on health, acknowledging that it is much more than the absence of disease. They accepted a conceptualization that considers health as the ability of individuals and communities to adapt and manage the physical, mental, or social challenges faced throughout life [29]. This facilitated a much more effective and natural alignment between the family's goals, the views of the experts, and the collaborative decision-making model to develop an optimal action plan to improve health [27].

This shift to a health-focused approach to Silvana's life with intractable seizures enabled a transition from finding a cure or complete seizure control to achieving maximum levels of adaptation and self-management of an incurable condition through the activities illustrated in Table 1. Throughout the process, they agreed to monitor their levels of self-reported health by asking themselves the following question: "In general, would you say that your health is poor, fair, good, very good, or excellent?" Answering poor or fair represented negative health, whereas good, very good, or excellent was regarded as reflecting positive health.

Initially, Ricardo's self-reports were consistently negative; Silvana's and Leon's were consistently positive; and Denise's fluctuated, depending on whether she spent more time with Ricardo or their children.

The intention was to achieve positive health self-ratings for all family members for at least six months, to consider the approach successful and worth sharing with other families and health professionals. Figure 1 summarizes the journey. 
Table 1. Efforts to generate maximum levels of adaptation and self-management within the context of health-focused collaborative decision making

\begin{tabular}{llll}
\hline Goals & $\begin{array}{l}\text { Health domains } \\
\text { Physical }\end{array}$ & Mental & Social \\
\hline Adaptation & $\begin{array}{l}\text { Companionship in enclosed spaces and } \\
\text { outdoors to prevent injuries }\end{array}$ & $\begin{array}{l}\text { Recognition of the incurable nature of the } \\
\text { disease }\end{array}$ & $\begin{array}{l}\text { Adapted high-school curriculum } \\
\text { On-site tutor to assist with academic tasks }\end{array}$ \\
$\begin{array}{l}\text { Self-manage- } \\
\text { ment }\end{array}$ & Optimal adherence to medication intake & $\begin{array}{l}\text { Family-focused counseling, yoga, and } \\
\text { meditation }\end{array}$ & $\begin{array}{l}\text { Initiation of a small business with a close } \\
\text { family friend }\end{array}$ \\
\hline
\end{tabular}

Figure 1. Key stages of the collaborative decision-making process within the context of participatory medicine.

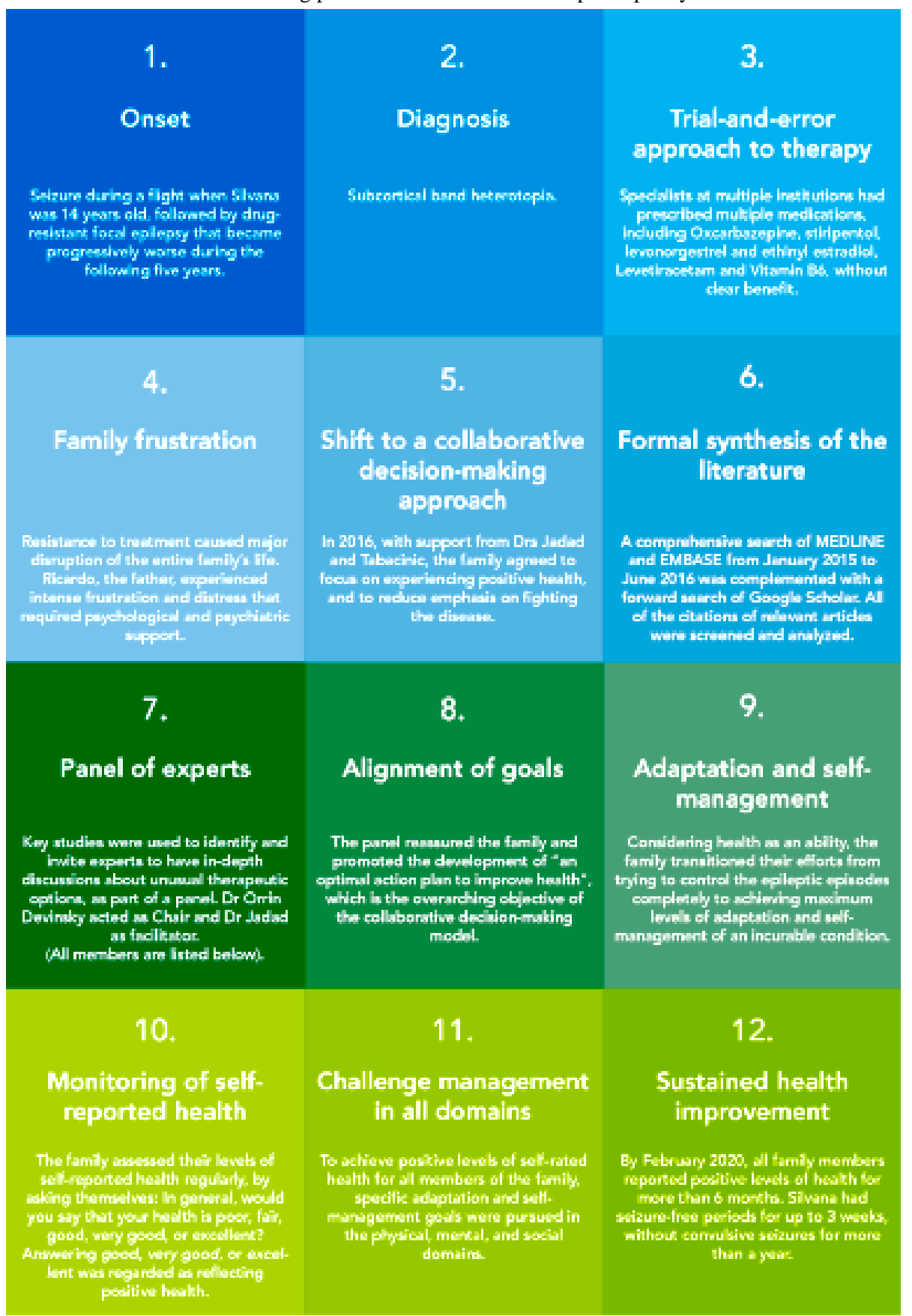

\section{Panel of Experts}

Orrin Dovinsky (Chair, neumologkst, and current main treating physicianl, Annapurna Poduri

'neurologist, main tresting physician during Silvans's teenage yearsl, Miriam Tabacinic 'physician and trusted family adviscor: Alejandro Jadad fotrysician, expert in evidence-based and collabcrative decision-making), Eric Kossoff (pediatric ncurologist, with interest in noncharmacological

intervertions), Lieven Lagae (neurclogist with interest in drug-resistant epilepsy), and Fergus

Rugg-Gunnfor ineunologist with interest in new and non-pharmacological intementions for epilepsy: 
From the physical perspective, the diet added little value in seizure control despite sustained strict adherence, and medication reduced seizure frequency and duration without eliminating them. Therefore, the collective objective switched to reducing bodily injuries while more drugs were tried following a systematic trial-and-error approach.

From the mental point of view, the panel contributed significantly to Ricardo's acceptance that Silvana's condition was incurable and that she was receiving the best available therapies. Subsequently, the family engaged in individual yoga and meditation training, and group counseling to identify and set boundaries, which facilitated their collective adaptation to living with an intractable chronic condition. Silvana was encouraged and supported to build self-confidence, and to develop new ways to manage fears and strategies to respond to frustrating situations calmly. The entire family engaged in activities to reduce the reinforcing of Silvana's sick role and to explore spiritual practices. The latter were particularly relevant for Ricardo, who decided to reconnect to his religious roots, finding solace and new sources of strength to deal with stress and to eradicate his guilt.

Socially, Silvana completed her high-school bilingual education with an adapted curriculum and support from an on-site tutor. Based on Silvana's enjoyment of tasks requiring attention to detail, her family supported the creation of a small business focused on the manufacture and commercialization of one-of-a-kind fashion accessories with a close family friend, which proved that it would be possible for her to make a living doing something she likes.

Soon, all of these changes became part of their normal daily living, and their self-reported health status had stabilized at positive levels for all family members (Figure 2). Silvana summarized the situation by stating, "I feel better than I did before now that I have changed my habits. Yoga helps me concentrate on my breathing, and increases my awareness level. My family helps me by providing me with loving support and balance in my life."

Figure 2. Denise, Silvana, Ricardo, and León Caridi in 2020.

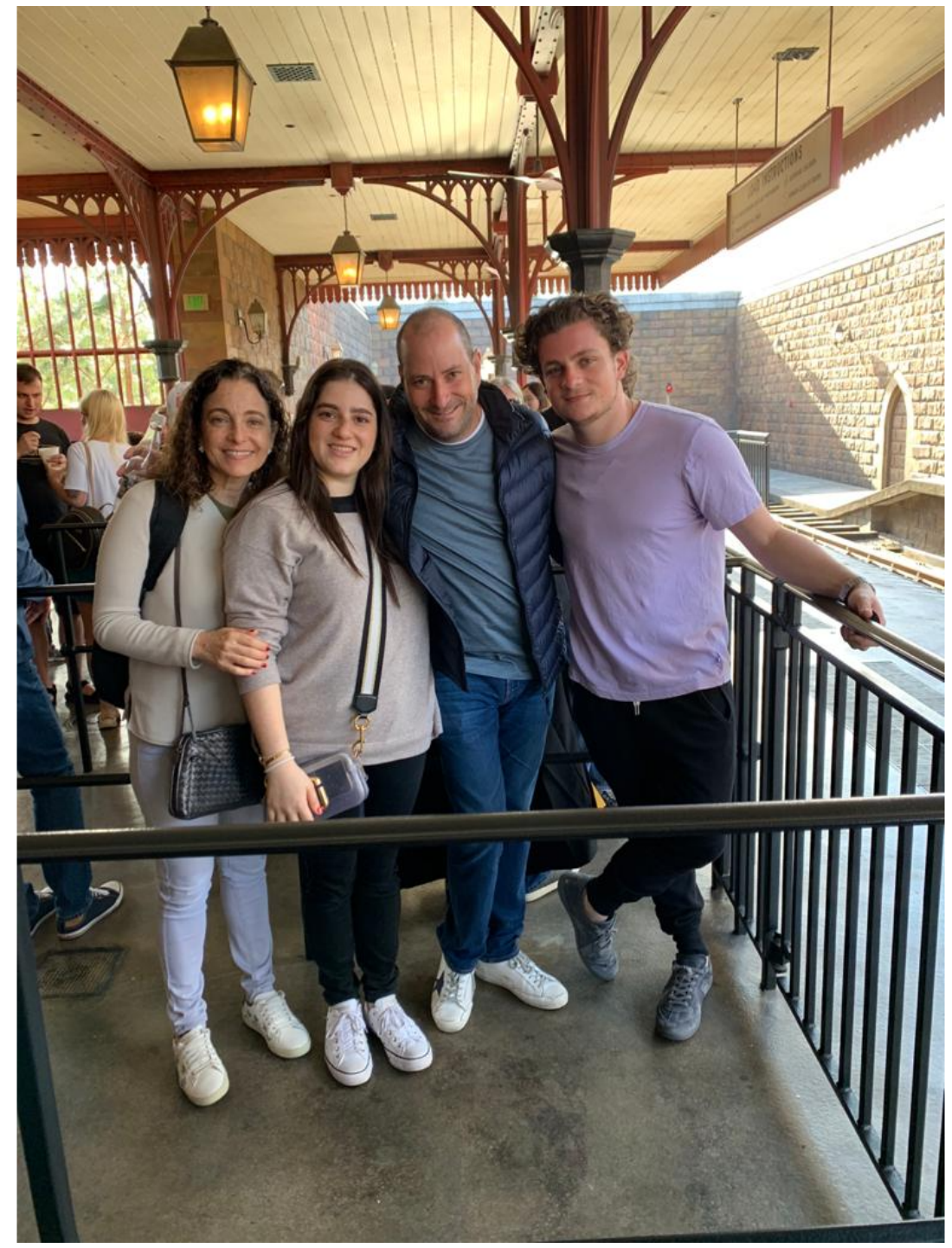

By February 2020, Silvana was taking lacosamide (400 mg/day), clobazam (40 mg/day), and vigabatrin (1750 mg/day), enjoying a significant and sustained reduction in her seizures. The most severe seizures caused head drop with impaired awareness for up to 30 seconds. She could go for up to 3 weeks seizure free. 
Anxiety and stress remained triggers, and when she reduced her daily yoga activity, her seizures would worsen.

By the time this article was submitted, Silvana was working with a cousin in her photography and graphic design company, designing a family cookbook. At that point, she had been free of convulsive seizures for more than a year.

\section{Discussion}

This case illustrates how collaborative decision making could enable a family and their health professionals to use different relationship models, to explore therapeutic options within the broad domain of traditional and nontraditional medicine. The panel enabled Ricardo to benefit from the informative model by asking the participating specialists to answer his questions until he was reassured that the family's decisions were based on the best knowledge. Once this was achieved, the panel promoted two-way knowledge exchange, shifting to a shared decision-making model, and focused on identifying the best course of action. Once there was agreement around the best course to follow, the family comfortably switched to a slightly paternalistic relationship, especially for diet implementation and systematic medication changes.

Conceptualizing health as the ability to adapt and self-manage the physical, mental, and social challenges created by the subcortical band heterotopias added value in fundamental ways. First, the family shifted years of emphasis on the disease to concentrating on achieving optimal levels of health per se. Part of this process was giving themselves permission to deviate from the cure at all cost paradigm. Second, this conceptualization helped the family recognize that all of them-not just Silvana-needed support to enhance their capacity to adapt to her intractable epilepsy. Lastly, it showcased how team effort can make positive health possible even in the presence of chronic, incurable diseases, opening new avenues for patients and clinicians to harness the power of collaboration as the essence of participatory medicine.

\section{Acknowledgments}

The authors thank the members of the panel of specialists_-including Drs Eric Kossoff, Lieven Lagae, and Fergus Rugg-Gunn for their commitment, professionalism, and interest in guiding the Caridi family during one of the most stressful periods of their decision-making process; and Mr Vladimir Angert for guiding the family's efforts to strengthen their mental health and to explore spiritual practices. The Caridi Family includes Ricardo, Denise, Leon and Silvana.

\section{Conflicts of Interest}

None declared.

\section{References}

1. Szasz TS, Knoff WF, Hollender MH. The doctor-patient relationship and its historical context. Am J Psychiatry 1958 Dec;115(6):522-528. [doi: 10.1176/ajp.115.6.522]

2. Launer J. Anna O and the "talking cure". QJM 2005;98(6):465-466.

3. Szasz TS, Hollender MH. A contribution to the philosophy of medicine. AMA Arch Intern Med 1956 May 01;97(5):585. [doi: 10.1001/archinte.1956.00250230079008]

4. Degner LF, Sloan JA. Decision making during serious illness: what role do patients really want to play? J Clin Epidemiol 1992 Sep;45(9):941-950. [doi: 10.1016/0895-4356(92)90110-9]

5. Charles C, DeMaio S. Lay participation in health care decision making: a conceptual framework. Journal of Health Politics, Policy and Law 1993 Jan 01;18(4):881-904. [doi: 10.1215/03616878-18-4-881]

6. Glouberman S. The Mechanical Patient: Finding a More Human Model of Health. New York: Productivity Press; 2018.

7. Veatch RM. Models for ethical medicine in a revolutionary age. The Hastings Center Report 1972 Jun;2(3):5-7. [doi: $10.2307 / 3560825]$

8. Barry MJ, Edgman-Levitan S. Shared decision making--pinnacle of patient-centered care. N Engl J Med 2012 Mar;366(9):780-781. [doi: 10.1056/nejmp1109283]

9. Fried TR. Shared decision making--finding the sweet spot. N Engl J Med 2016 Jan 14;374(2):104-106 [FREE Full text] [doi: 10.1056/NEJMp1510020] [Medline: 26760081]

10. Shay LA, Lafata JE. Where is the evidence? A systematic review of shared decision making and patient outcomes. Med Decis Making 2014 Oct 28;35(1):114-131. [doi: 10.1177/0272989x14551638]

11. Hoffmann TC, Montori VM, Del Mar C. The connection between evidence-based medicine and shared decision making. JAMA 2014 Oct 01;312(13):1295-1296. [doi: 10.1001/jama.2014.10186]

12. Charles C, Gafni A, Whelan T. Shared decision-making in the medical encounter: what does it mean? (or it takes at least two to tango). Social Science \& Medicine 1997 Mar;44(5):681-692. [doi: 10.1016/s0277-9536(96)00221-3]

13. Bergsma J, Thomasma D. Autonomy and Clinical Medicine: Renewing the Health Professional Relation with the Patient. Berlin: Springer Science \& Business Media; 2000.

14. Charles C, Whelan T, Gafni A. What do we mean by partnership in making decisions about treatment? BMJ 1999 Sep 18;319(7212):780-782. [doi: $10.1136 / \mathrm{bmj} .319 .7212 .780$ ] 
15. Emanuel EJ. Four models of the physician-patient relationship. JAMA 1992 Apr 22;267(16):2221-2226. [doi: 10.1001/jama.1992.03480160079038]

16. Deber RB, Kraetschmer N, Urowitz S, Sharpe N. Do people want to be autonomous patients? Preferred roles in treatment decision-making in several patient populations. Health Expect 2007 Sep;10(3):248-258. [doi: 10.1111/j.1369-7625.2007.00441.x]

17. Anderson D. Shared Decision-Making Programs: Descriptive Analysis of Experience With Shared Decision-Making Programs in VA. York: Centre for Reviews and Dissemination; 1997.

18. Martínez-González NA, Neuner-Jehle S, Plate A, Rosemann T, Senn O. The effects of shared decision-making compared to usual care for prostate cancer screening decisions: a systematic review and meta-analysis. BMC Cancer 2018 Oct 22;18(1):1015. [doi: 10.1186/s12885-018-4794-7]

19. Wieringa TH, Kunneman M, Rodriguez-Gutierrez R, Montori VM, de Wit M, Smets EMA, et al. A systematic review of decision aids that facilitate elements of shared decision-making in chronic illnesses: a review protocol. Syst Rev 2017 Aug 7;6(1):155. [doi: 10.1186/s13643-017-0557-9]

20. Tousignant-Laflamme Y, Christopher S, Clewley D, Ledbetter L, Cook CJ, Cook CE. Does shared decision making results in better health related outcomes for individuals with painful musculoskeletal disorders? A systematic review. Journal of Manual \& Manipulative Therapy 2017 May 09;25(3):144-150. [doi: 10.1080/10669817.2017.1323607]

21. Rose A, Rosewilliam S, Soundy A. Shared decision making within goal setting in rehabilitation settings: a systematic review. Patient Education and Counseling 2017 Jan;100(1):65-75. [doi: 10.1016/j.pec.2016.07.030]

22. Hauser K, Koerfer A, Kuhr K, Albus C, Herzig S, Matthes J. Outcome-relevant effects of shared decision making: a systematic review. Deutsches Ärzteblatt International 2015;112(40):665. [doi: 10.3238/arztebl.2015.0665]

23. Boss EF, Mehta N, Nagarajan N, Links A, Benke JR, Berger Z, et al. Shared decision making and choice for elective surgical care: a systematic review. Otolaryngol Head Neck Surg 2015 Dec 08;154(3):405-420. [doi: $10.1177 / 0194599815620558]$

24. Clarke G, Hall RT, Rosencrance G. Physician-patient relations: no more models. The American Journal of Bioethics 2004 Jun;4(2):W16-W19. [doi: 10.1162/152651604323097934]

25. Chewning B, Bylund CL, Shah B, Arora NK, Gueguen JA, Makoul G. Patient preferences for shared decisions: a systematic review. Patient Education and Counseling 2012 Jan;86(1):9-18. [doi: 10.1016/j.pec.2011.02.004]

26. Edozien L. Self-Determination in Health Care: A Property Approach to the Protection of Patients' Rights. Abingdon: Routledge; 2015.

27. O'Grady L, Jadad A. Shifting from shared to collaborative decision making: a change in thinking and doing. Journal of Participatory Medicine 2010;2:1-6 [FREE Full text]

28. Anonymous. Genetics Home Reference. 2019. Subcortical band heterotopia URL: https://ghr.nlm.nih.gov/condition/ subcortical-band-heterotopia [accessed 2020-05-31]

29. Huber M, Knottnerus JA, Green L, Horst HVD, Jadad AR, Kromhout D, et al. How should we define health? BMJ 2011 Jul 26;343(jul26 2):d4163. [doi: 10.1136/bmj.d4163]

Edited by D van Leeuwen, S Woods; submitted 24.12.19; peer-reviewed by N Finn, J Pereira Loureiro; comments to author 26.03.20; revised version received 07.05.20; accepted 08.05.20; published 22.06.20

Please cite as:

Caridi Family, Poduri A, Devinsky O, Tabacinic M, Jadad AR

Experiencing Positive Health, as a Family, While Living With a Rare Complex Disease: Bringing Participatory Medicine Through Collaborative Decision Making Into the Real World

J Participat Med 2020;12(2):e17602

URL: http://jopm.jmir.org/2020/2/e17602/

doi: $\underline{10.2196 / 17602}$

PMID:

(C) Caridi Family, Annapurna Poduri, Orrin Devinsky, Miriam Tabacinic, Alejandro R Jadad. Originally published in Journal of Participatory Medicine (http://jopm.jmir.org), 22.06.2020. This is an open-access article distributed under the terms of the Creative Commons Attribution License (https://creativecommons.org/licenses/by/4.0/), which permits unrestricted use, distribution, and reproduction in any medium, provided the original work, first published in Journal of Participatory Medicine, is properly cited. The complete bibliographic information, a link to the original publication on http://jopm.jmir.org, as well as this copyright and license information must be included. 